\title{
Take a deep breath and everything will be all right...
}

\author{
Konrad Hoetzenecker, MD, PhD, and Walter Klepetko, MD
}

\author{
From the Division of Thoracic Surgery, Medical University of Vienna, Vienna, Austria. \\ Disclosures: Authors have nothing to disclose with regard to commercial support. \\ Received for publication Aug 2, 2017; accepted for publication Aug 8, 2017; available ahead of print Sept 12, \\ 2017. \\ Address for reprints: Konrad Hoetzenecker, MD, PhD, Division of Thoracic Surgery, Medical University of \\ Vienna, Waehringer Guertel 18-20, 1090 Vienna, Austria (E-mail: konrad.hoetzenecker@meduniwien.ac.at). \\ J Thorac Cardiovasc Surg 2017; 154:2152 \\ $0022-5223 / \$ 36.00$ \\ Copyright $\subset 2017$ by The American Association for Thoracic Surgery \\ http://dx.doi.org/10.1016/j.jtcvs.2017.08.008
}

Targeted therapies are currently big sellers in the field of oncology. Tailoring drugs to the needs of each individual patient is a tempting approach. In the area of transplantation, the term "targeted therapy" can be interpreted differently and describes the vision of administering immunosuppressive drugs to the allograft in a highly localized way. Thus, collateral damage to other organs can be minimized.

In this issue, Das and colleagues ${ }^{1}$ describe the use of a new, inhaled tacrolimus formulation. By thin film freezing using lactose as a stabilizer, a brittle matrix is produced. This has good aqueous solubility and a small dispersion size. Thus, the new formulation potentially reaches the most distal airways. This nanoparticle tacrolimus (nTac) was tested in a rat single-lung transplant model and was compared with a conventional systemic tacrolimus therapy. Inhaled nTAC-treated rats had similar allograft rejection scores but significantly lower tacrolimus burden in kidney and blood specimens compared with the control group.

Contrary to inhaled cyclosporine, which has already been tested successfully in lung transplant recipients, research on inhaled formulations of tacrolimus is lagging. ${ }^{2}$ Only a few animal studies have been published, almost exclusively using a simple nebulized formulation of dissolved tacrolimus powder. The current work is based on previous research from the same group providing detailed characterizations of the new nTAC and its pharmacokinetics. ${ }^{3,4}$ By linking the originally lipophilic tacrolimus with lactose, a nanostructured solid dispersion of an amorphous structure has been produced that has significantly better solubility in lung fluid. The current study presents the next step toward a future clinical application.

Before immunosuppressants can be used in a clinical context, there is a long road ahead with many questions still on the table. The tolerability of inhaled nanoparticle formulations is currently unknown. Nebulized cyclosporine led to severe airway hyperresponsiveness and study dropout in $7 \%$ of patients in a randomized controlled trial. ${ }^{2}$ Also, nebulized liposomal amphothericine-B has to be frequently discontinued in a low but constant number of lung

\section{References} 2017; 154:2144-51.e1. Med. 2006;354:141-50. 1057-66. 523-30.

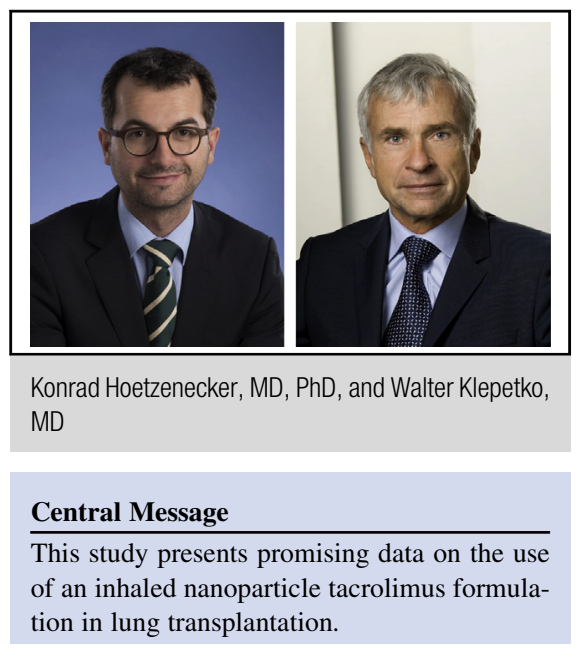

See Article page 2144.

transplant recipients. ${ }^{5}$ Although lactose as the stabilizing agent of the described nTAC is considered generally safe for use in lungs, the safety profile of a long-term application of inhaled nTAC is elusive. There is at least some evidence suggesting that chronic exposure of the lungs to nanoparticles may trigger pulmonary fibrosis.

The authors should be congratulated on this wellconducted animal study, which will hopefully stimulate the search for alternative administration routes of immunosuppressive drugs. Their findings can be considered an important part in the puzzle for future targeted therapies in lung transplantation.

1. Das NA, Peters JI, Simmons JD, Wang Y, O'Donnell KP, DeArmond DT, et al. The efficacy of inhaled nanoparticle tacrolimus in preventing rejection in an orthotopic rat lung transplant model. J Thorac Cardiovasc Surg.

2. Iacono AT, Johnson BA, Grgurich WF, Youssef JG, Corcoran TE, Seiler DA, et al. A randomized trial of inhaled cyclosporine in lung-transplant recipients. $N$ Engl J

3. Watts AB, Cline AM, Saad AR, Johnson SB, Peters JI, Williams RO III. Characterization and pharmacokinetic analysis of tacrolimus dispersion for nebulization in a lung transplanted rodent model. Int J Pharm. 2010;384:46-52.

4. Sinswat P, Overhoff KA, McConville JT, Johnston KP, Williams RO III. Nebulization of nanoparticulate amorphous or crystalline tacrolimussingle-dose pharmacokinetics study in mice. Eur J Pharm Biopharm. 2008;69:

5. Monforte V, Ussetti P, Gavalda J, Bravo C, Laporta R, Len O, et al. Feasibility, tolerability, and outcomes of nebulized liposomal amphotericin B for Aspergillus infection prevention in lung transplantation. J Heart Lung Transplant. 2010;29:

6. Byrne JD, Baugh JA. The significance of nanoparticles in particle-induced pulmonary fibrosis. Mcgill J Med. 2008;11:43-50. 